\section{OVERWEIGHT/OBESE CHILDREN, DROPPING OUT OF THERAPY, SHOW A HIGHER METABOLIC RISK PROFILE}

C. de Beaufort ${ }^{1}$, H. Samouda ${ }^{2}$, J. Jacobs ${ }^{2}$, J.F. Vervier ${ }^{3}$, V. Bocquet ${ }^{2}$, U. Schierloh ${ }^{1}$, G. Gilson ${ }^{4}$, OSPEL study group

${ }^{1}$ DECCP, Clinique Pédiatrique/CHL, ${ }^{2}$ Department of Public Health, Centre de Recherche Publique-

Santé, ${ }^{3}$ Service de Pédopsychiatrie, Clinique Pédiatrique/CHL, ${ }^{4}$ Department of Clinical Biology, Centre Hospitalier de Luxembourg,

Luxembourg, Luxembourg

Objectives: Compare the characteristics of children, who were compliant or non-compliant in two different therapeutic programs coping with overweight/obesity

Methodology: Self-referred overweight and obese children/adolescents, were invited to participate and were randomised to group or individual therapy for a period of 4 months. Group therapy (GT) was a multidisciplinary, intensive therapy, including sport, healthy food intake and psychological counselling. Individual treatment (IT) was made to measure and consisted of counselling of the child and its family on healthy lifestyle.( Dietary advice and psychological support was available). At onset Family Affluence Scale (FAS), anthropometric parameters, glucose and fat metabolism were investigated. The study was approved by the National Medical Ethical Committee (CNER).

Results: In total, 192 children and adolescents participated with personal and parental informed consent (age range $7-17$ years; F: 53.6\%). Within the first 4 months, $14.5 \%$ dropped out of therapy in both groups $(n=70)$ with no difference between the two treatment groups. No difference in FAS score was observed between the two groups. Drop outs had a significantly higher BMI Z-score at onset, compared to those who continued $(p=0.001 ; 2.85$ \pm 0.45 vs $2.48 \pm 0.58$ )

They had as well higher insulin and HOMA levels ( 4.37 vs 3.04), higher triglycerides and higher fibrinogen.

Discussion: Children dropping out of specially developed ambulatory outpatient programs are more obese and present higher risk factors for insulin resistance and cardiovascular pathology. Alternative programs may be needed to reach this group.

\section{REGIONAL CORTICAL SURFACE AREA RELATES TO IQ IN YOUNG ADULTS BORN PRETERM WITH VERY LOW BIRTH WEIGHT (VLBW)}

J. Skranes ${ }^{1,2,3}$, G.C. Løhaugen ${ }^{1,2}$, M. Martinussen ${ }^{1}$, A. Håberg ${ }^{4,5,6}$, A.M. Dale ${ }^{4,7}$, A.-M. Brubakk ${ }^{1,3}$

${ }^{1}$ Dept of Lab Medicine, Children's and Women's Health, Norwegian University of Science and Technology, Trondheim, ${ }^{2}$ Dept of Pediatrics, Sørlandet Hospital, Arendal, ${ }^{3}$ Dept of Pediatrics, St Olav's University Hospital, ${ }^{4}$ Dept of Circulation and Medical Imaging, ${ }^{5}$ Dept of Neuroscience, Norwegian University of Science and Technology, ${ }^{6}$ Dept of Diagnostic Imaging, MR Center, St Olav's University Hospital, Trondheim, Norway, ${ }^{7} \mathrm{MIL}$, Dept. of Neurosciences and Radiology, University of AarhusSan Diego, San Diego, CA, USA

Background and aims: Perinatal brain injury in very low birth weight (VLBW) preterms includes grey and white matter damage that affects brain development, and is associated with neurocognitive deficits that persist into adulthood. The aim of study was to investigate the relationship between cortical surface area expansion and different IQ indices in VLBW young adults.

Methods: 49 VLBW (birth weight $\leq 1500$ grams) and 59 term born controls were examined at the age of 19 with Wechsler Adult Intelligence Scale WAIS-III and MRI. An automated MRI technique at 1.5 Tesla for morphometric analyses of regional cortical expansion was performed.

Results: Reduced cortical surface area in the VLBW young adults compared with controls were seen mainly in the dorsolateral frontal, temporal and parietal regions, with a strong influence from birth weight, far less from gestational age. The variability in Full IQ in the VLBW group was associated with reduced surface area in specific cortical regions of the brain, with a pattern similar to the localization of the group differences. The IQ indices that corresponded the most to the associations were the Working Memory Index and the Processing Speed Index. No associations were seen between surface area and IQ indices in the control group.

Conclusions: This is the first study that links cognitive deficits to deviations in regional cortical development seen as significantly reduced brain surface area in young adults born with VLBW compared to term born controls. 